Supporting information for

\title{
Highly functionalized cyclopentanes from meso bicyclic hydrazines. A rapid access to mannosidase inhibitors.
}

\author{
C. Bournaud, ${ }^{\S}$ D. Robic, ${ }^{\#}$ M. Bonin, ${ }^{\S}$ and L. Micouin ${ }^{\S} *$
}

Laboratoire de Chimie Thérapeutique, UMR 8638 associée au CNRS et à l'Université René Descartes, Faculté des Sciences Pharmaceutiques et Biologiques 4, av de l'Observatoire, 75270 Paris cedex 06 (France) and Laboratoire de Cristallographie et RMN Biologiques, UMR 8015 associée au CNRS et à l'Université René Descartes, Faculté des Sciences Pharmaceutiques et Biologiques 4, av de l'Observatoire, 75270 Paris cedex 06 (France)

\section{Table of Contents :}

S2. Experimental procedures and characterizations of compounds 2, 3, 4, 6, 7, 8, 9, 10.

S7. Biological activities

S8. NMR Spectra 


\section{Experimental procedures}

\section{3-oxo-2,3,7,7a-tetrahydro-4aH-cyclopenta[1,3,4] oxadiazine-1-carboxylic acid benzyl}

ester 2 : Concentrated aqueous sulfuric acid $(50 \mu \mathrm{L})$ was added to $\mathbf{1}(2 \mathrm{~g}, 5.5 \mathrm{mmol})$ in 2,2,2trifluoroethanol $(10 \mathrm{~mL})$. The mixture was stirred during $20 \mathrm{~min}$, water was added $(5 \mathrm{~mL})$ and the solution was basified with $\mathrm{K}_{2} \mathrm{CO}_{3}$ until $\mathrm{pH}$ 12. Solvent was evaporated and $\mathrm{CH}_{2} \mathrm{Cl}_{2}(20$ $\mathrm{mL})$ and water $(10 \mathrm{~mL})$ were added to the crude. Organic layer was separated and the aqueous phases were extracted by $\mathrm{CH}_{2} \mathrm{Cl}_{2}(3 \times 20 \mathrm{~mL})$. Organic layers were dried over $\mathrm{MgSO}_{4}$, the solvent was evaporated and the crude was purified by silica gel chromatography (elution conditions: cyclohexane/EtOAc 70/30) to give 2 (1.36 g, $4.96 \mathrm{mmol}) .{ }^{1} \mathrm{H}$ NMR (400 MHz, $\left.\mathrm{CDCl}_{3}, 50{ }^{\circ} \mathrm{C}\right) \delta 2.54(\mathrm{br} \mathrm{d}, J=17.8 \mathrm{~Hz}, 1 \mathrm{H}), 2.66($ br d, $J=17.8 \mathrm{~Hz}, 1 \mathrm{H}), 4.52$ (br s, $\left.1 \mathrm{H}\right)$, $5.16(\mathrm{~d}, J=12.2 \mathrm{~Hz}, 1 \mathrm{H}), 5.20(\mathrm{~d}, J=12.2 \mathrm{~Hz}, 1 \mathrm{H}), 5.46(\mathrm{~m}, 1 \mathrm{H}), 5.84(\mathrm{~m}, 1 \mathrm{H}), 6.06(\mathrm{~m}$, 1H), 6.90 (br s, 1H), 7.36 (br s, $5 \mathrm{H}) ;{ }^{13} \mathrm{C} \mathrm{NMR}\left(100 \mathrm{MHz}, \mathrm{CDCl}_{3}\right.$ ) $\delta$ 36.9, 58.1, 68.0, 83.0, 128.0, 128.2, 128.4, 128.6, 135.2, 135.7, 155.4, 156.3 ; IR $\left(\mathrm{cm}^{-1}\right) 3411,1777,1746,1488$, 1324, 1028; MS (ESI) $297\left(\mathrm{MNa}^{+}\right)$. Anal. Calcd for $\mathrm{C}_{14} \mathrm{H}_{14} \mathrm{~N}_{2} \mathrm{O}_{4}: \mathrm{C}, 61.31 ; \mathrm{H}, 5.14 ; \mathrm{N}, 10.21$ Found: C, 61.47, H, 5.29; N, 10.05.

\section{7-Hydroxy-3-oxo-2,3,7,7a-tetrahydro-4aH-cyclopenta[1,3,4]oxadiazine-1-carboxylic acid} benzyl ester 6: Oxadiazine 2 ( $879 \mathrm{mg}, 3.2 \mathrm{mmol})$ was dissolved in diglyme $(9 \mathrm{~mL})$, followed by $\mathrm{KH}_{2} \mathrm{PO}_{4}(73 \mathrm{mg}, 0.54 \mathrm{mmol})$, selenium dioxide $(356 \mathrm{mg}, 3.2 \mathrm{mmol})$ and sand. The flask was placed into a hot $\left(170{ }^{\circ} \mathrm{C}\right)$ oil bath, stirred under reflux for $45 \mathrm{~min}$ and selenium dioxide (200 mg, $3.6 \mathrm{mmol}$ ) was added. The mixture was stirred for $40 \mathrm{~min}$, the oil bath was removed and the flask was cooled to room temperature for several hours. The reaction mixture was filtered over celite, rinsed twice by $\mathrm{CH}_{2} \mathrm{Cl}_{2}(20 \mathrm{~mL})$ and EtOAc $(50 \mathrm{~mL})$. Organic solvent were evaporated under reduced pressure, and the crude was purified by silica gel chromatography (elution conditions: cyclohexane/EtOAc 45/55) to give 6 (645 mg, 2.22 
mmol). ${ }^{1} \mathrm{H}$ NMR (400 MHz, $\left.\mathrm{CDCl}_{3}\right) \delta 4.24$ (br s, $\left.1 \mathrm{H}\right), 4.88$ (br s, $\left.1 \mathrm{H}\right), 5.15(\mathrm{~d}, J=12.0 \mathrm{~Hz}$, 1H), 5.19 (d, $J=12.0 \mathrm{~Hz}, 1 \mathrm{H}), 5.58$ (br s, 1H), 6.06 (br s, 1H), 6.18 (br s, 1H), 7.17 (br s, 1H), $7.36(\mathrm{~m}, 5 \mathrm{H}) ;{ }^{1} \mathrm{H}$ NMR (400 MHz, DMSO d6 + $\left.\mathrm{D}_{2} \mathrm{O}, 70{ }^{\circ} \mathrm{C}\right) \delta 3.99(\mathrm{br} \mathrm{d}, J=7.25 \mathrm{~Hz}$, 1H), 4.67 (br s, 1H), 5.14 (br s, 2H), 5.60 (br d, $J=6.49 \mathrm{~Hz}, 1 \mathrm{H}), 6.00$ (br d, $J=5.11 \mathrm{~Hz}$, 1H), 6.15 (br d, $J=4.4 \mathrm{~Hz}, 1 \mathrm{H}), 7.37$ (br s, 5H); ${ }^{13} \mathrm{C} \mathrm{NMR}\left(75 \mathrm{MHz}, \mathrm{CDCl}_{3}\right) \delta$ 66.2, 68.3, 78.0, 81.7, 128.2, 128.5, 128.6, 131.7, 135.1, 138.1, 155.5, 155.7; IR $\left(\mathrm{cm}^{-1}\right) 3638,1731,1540$, 1506, 1456, 1418, 1257, 1208; MS (CI) $291\left(\mathrm{MH}^{+}\right)$. HRMS (ES+) for $\mathrm{C}_{14} \mathrm{H}_{14} \mathrm{~N}_{2} \mathrm{O}_{5} \mathrm{Na}$ : Calcd.: 313.0800, Found: 313.0798.

\section{7-Methoxy-2-methyl-3-oxo-2,3,7,7a-tetrahydro-4aH-cyclopenta[1,3,4]oxadiazine-1-}

carboxylic acid benzyl ester 7 : Potassium hydride $(0.2 \mathrm{~mL}, 30 \%$ mineral oil suspension, $2.17 \mathrm{mmol})$ was added to compound $6(260 \mathrm{mg}, 0.896 \mathrm{mmol})$ in anhydrous THF $(15 \mathrm{~mL})$ under argon. The reaction mixture was stirred for $30 \mathrm{~min}$ and $\mathrm{MeI}(0.2 \mathrm{~mL}, 3.21 \mathrm{~mL})$ was added. The mixture was stirred for $3 \mathrm{~h}$ and $\mathrm{KH}(0.2 \mathrm{~mL}, 2.17 \mathrm{mmol})$ and $\mathrm{MeI}(0.2 \mathrm{~mL}, 3.21$ mmol) were added. The solution was stirred overnight, and treated by a saturated aqueous $\mathrm{NaCl}$ solution $(7 \mathrm{~mL})$ and EtOAc $(5 \mathrm{~mL})$. Organic layer was separated and the aqueous phases were extracted by EtOAc $(3 \times 10 \mathrm{~mL})$. Organic layers were dried over $\mathrm{MgSO}_{4}$, the solvent was evaporated and the crude was purified by silica gel chromatography (elution conditions: cyclohexane/EtOAc 60/40) to give 7 (212 mg, $0.67 \mathrm{mmol}) .{ }^{1} \mathrm{H}$ NMR (400 MHz, $\mathrm{CDCl}_{3}$, conformers) $\delta 3.15-3.33(\mathrm{~m}, 6 \mathrm{H}), 4.10-4.39(\mathrm{~m}, 1 \mathrm{H}), 4.24-4.69(\mathrm{~m}, 1 \mathrm{H}), 4.97-5.37$ $(\mathrm{m}, 2 \mathrm{H}), 5.46-5.60(\mathrm{~m}, 1 \mathrm{H}), 5.92-6.30(\mathrm{~m}, 2 \mathrm{H}), 7.36(\mathrm{~m}, 5 \mathrm{H}) .{ }^{13} \mathrm{C} \mathrm{NMR}\left(75 \mathrm{MHz}, \mathrm{CDCl}_{3}\right.$, conformers) $\delta 38.3,38.9,57.0,61.1,62.8,63.5,68.7,81.4,81.6,85.8,87.3,87.6,128.0$, 128.1, 128.5, 128.6, 132.7, 133.3, 133.6, 135.3, 155.8. IR $\left(\mathrm{cm}^{-1}\right): 2940,1771,1716,1540$, $1498,1456,1418,1385,1339,1213,1180,1092,1037 . \mathrm{MS}(\mathrm{CI}) 319\left(\mathrm{MH}^{+}\right)$. Anal. Calcd for $\mathrm{C}_{16} \mathrm{H}_{18} \mathrm{~N}_{2} \mathrm{O}_{5}: \mathrm{C}, 60.37 ; \mathrm{H}, 5.70 ; \mathrm{N}, 8.80$ Found : C, $60.30 ; \mathrm{H}, 5.83$; N, 8.71. 


\section{5,6-Dihydroxy-7-methoxy-2-methyl-3-oxo-hexahydro-cyclopenta[1,3,4]oxadiazine-1-}

carboxylic acid benzyl ester 3 : NMO (300 mg, $1.39 \mathrm{mmol})$, osmium tetroxyde $(2.5 \% \mathrm{w} / \mathrm{w}$, $1.1 \mathrm{~mL}, 0.087 \mathrm{mmol})$ were added to compound $7(490 \mathrm{mg}, 1.54 \mathrm{mmol})$ in a $(8 / 1)$ mixture of THF/water $(11.8 \mathrm{~mL})$. The mixture was stirred for seven days at room temperature. The solution was treated by aqueous hydrochloric acid $3 \mathrm{~N}(20 \mathrm{~mL})$, aqueous sodium hydrogenosulfite $15 \%(8 \mathrm{~mL})$ and EtOAc $(20 \mathrm{~mL})$. Organic layer was separated and the aqueous phases were extracted by EtOAc $(3 \times 20 \mathrm{~mL})$. Organic layers were dried over $\mathrm{MgSO}_{4}$, the solvent was evaporated and the crude was purified by silica gel chromatography (elution conditions : $\left.\mathrm{CH}_{2} \mathrm{Cl}_{2} / \mathrm{MeOH} 95 / 5\right)$ to give 3 (540 mg, $1.53 \mathrm{mmol}$ ). ${ }^{1} \mathrm{H}$ NMR (400 $\mathrm{MHz}, \mathrm{CDCl}_{3}$, conformers) $\delta 3.19-3.35(\mathrm{~m}, 6 \mathrm{H}), 3.81-3.85(\mathrm{~m}, 1 \mathrm{H}), 4.09-4.29(\mathrm{~m}, 3 \mathrm{H}), 4.77-$ $4.92(\mathrm{~m}, 1 \mathrm{H}), 5.12-5.30(\mathrm{~m}, 2 \mathrm{H}), 7.35(\mathrm{~m}, 5 \mathrm{H}) ;{ }^{13} \mathrm{C} \mathrm{NMR}\left(75 \mathrm{MHz}, \mathrm{CDCl}_{3}\right.$, conformers $) \delta$ $35.8,37.4,38.1,57.6,57.8,61.7,62.6,63.3,68.4,69.3,72.7,73.2,73.7,74.6,74.8,75.6$, $75.7,76.2,82.6,85.0,85.5,127.7,128.0,128.3,128.5,129.6,134.8,135.5,153.9,155.1$, 155.5, 155.8, 157.7; IR $\left(\mathrm{cm}^{-1}\right) 3194,3072,1772,1725,1537,1448,1378,1331,1178 ; \mathrm{MS}$ (CI) $353\left(\mathrm{MH}^{+}\right)$. Anal. Calcd for $\mathrm{C}_{16} \mathrm{H}_{20} \mathrm{~N}_{2} \mathrm{O}_{7}, \frac{1 / 2}{2} \mathrm{H}_{2} \mathrm{O}$ : C, 53.18; H, 5.86; N, 7.75 Found: C, 53.23, H, 5.77; N, 7.62.

\section{5,6-Dihydroxy-7-methoxy-2-methyl-hexahydro-cyclopenta[1,3,4]oxadiazin-3-one}

Compound 3 (34 mg, $0.096 \mathrm{mmol}$ ) was stirred in methanol (3 mL) under hydrogen atmosphere in the presence of 5\% $\mathrm{Pd} / \mathrm{C}(3.6 \mathrm{mg})$ for $3 \mathrm{~h}$. The reaction mixture was filtrated on celite and the solvent was evaporated to give 8 as a colourless oil $(16 \mathrm{mg}, 0.073 \mathrm{mmol}) .{ }^{1} \mathrm{H}$ NMR (400 MHz, $\left.\mathrm{CDCl}_{3}, 50{ }^{\circ} \mathrm{C}\right) \delta 2.72(\mathrm{~s}, 3 \mathrm{H}), 3.42(\mathrm{~s}, 3 \mathrm{H}), 3.88$ (br. s, $\left.1 \mathrm{H}\right), 4.06(\mathrm{~d}, J=7.5$ $\mathrm{Hz}, 1 \mathrm{H}), 4.12(\mathrm{~m}, 1 \mathrm{H}), 4.23(\mathrm{~m}, 1 \mathrm{H}), 4.79(\mathrm{dd}, J=7.5,5.5 \mathrm{~Hz}, 1 \mathrm{H}) ;{ }^{13} \mathrm{C} \mathrm{NMR}(75 \mathrm{MHz}$, $\left.\mathrm{CD}_{3} \mathrm{OD}\right) \delta 36.3,58.2,63.9,74.3,76.1,76.9,86.9,159.1 ; \mathrm{IR}\left(\mathrm{cm}^{-1}\right) 3490,1742,1449,1417$, 
1102, 1076; MS (CI) $219\left(\mathrm{MH}^{+}\right)$. HRMS (ES+) for $\mathrm{C}_{8} \mathrm{H}_{14} \mathrm{~N}_{2} \mathrm{O}_{5} \mathrm{Na}$ : Calcd.: 241.0800 Found: 241.0809.

4-Amino-5-methoxy-cyclopentane-1,2,3-triol 4. An excess of Lithium was added to a cold $\left(-78{ }^{\circ} \mathrm{C}\right)$ solution of liquid $\mathrm{NH}_{3}(20 \mathrm{~mL})$. A solution of compound $3(150 \mathrm{mg}, 0.426 \mathrm{mmol}$ in $2 \mathrm{~mL}$ of dry degassed THF) was dropwise added to the resulting blue solution. The reaction mixture was stirred for $20 \mathrm{~min}$, the cooling bath was removed, and the solution was refluxed for 6 hours at - $33{ }^{\circ} \mathrm{C}$, water was slowly added until disappearance of the blue colour and ammonia was evaporated. The resulting solution was treated by concentrated aqueous solution of hydrochloric acid until $\mathrm{pH} 1$. The crude was first purified on a sulfonic acid resin exchange (DOWEX 50WX8-400), then on a carboxylic acid resin exchange (Amberlite CG50) using an aqueous $1 \mathrm{M}$ ammonia solution as an eluent, leading to 4 as a colourless oil (35 $\mathrm{mg}, 0.21 \mathrm{mmol}) .{ }^{1} \mathrm{H}$ NMR (400 MHz, $\left.\mathrm{CD}_{3} \mathrm{OD}\right) \delta 3.46$ (br. t, $\left.J=5.8 \mathrm{~Hz}, 1 \mathrm{H}\right), 3.57$ (s, 3H), $3.89(\mathrm{t}, J=5.3 \mathrm{~Hz}, 1 \mathrm{H}), 4.02(\mathrm{t}, J=5.2 \mathrm{~Hz}, 1 \mathrm{H}), 4.11($ br. $\mathrm{t}, J=4.3 \mathrm{~Hz}, 1 \mathrm{H}), 4.27(\mathrm{dd}, J=6.3$, $3.8 \mathrm{~Hz}, 1 \mathrm{H}) ;{ }^{13} \mathrm{C}$ NMR $\left(75 \mathrm{MHz}, \mathrm{CD}_{3} \mathrm{OD}\right) \delta 49.1,49.4,64.4,64.5,67.5,86.2$; MS (CI) 164 $\left(\mathrm{MH}^{+}\right)$. HRMS (ES+) for $\mathrm{C}_{6} \mathrm{H}_{14} \mathrm{NO}_{4}$ : Calcd.: 164.0923 Found: 164.0921.

4-Methoxy-5-(N'-methyl-hydrazino)-cyclopentane-1,2,3-triol 10. LiOH (84 mg, 2.2 mmol) was added to a solution of $3(85 \mathrm{mg}, 0.24 \mathrm{mmol})$ in a $2 / 1$ mixture of $\mathrm{THF} / \mathrm{H}_{2} \mathrm{O}(3 \mathrm{~mL})$ under argon atmosphere. After 22 hours stirring, the solution was acidified by a concentrated aqueous $\mathrm{HCl}$ solution until $\mathrm{pH} 1$. Solvent was evaporated, and the crude was purified on a sulfonic acid resin exchange (DOWEX 50WX8-400) an aqueous 1M ammonia solution as an eluent leading to $\mathbf{1 0}$ as a slightly yellow oil (45 mg, $0.23 \mathrm{mmol}) .{ }^{1} \mathrm{H}$ NMR (400 MHz, $\left.\mathrm{CD}_{3} \mathrm{OD}\right) \delta 2.93(\mathrm{~s}, 3 \mathrm{H}), 3.48(\mathrm{t}, J=6.0 \mathrm{~Hz}, 1 \mathrm{H}), 3.57(\mathrm{~s}, 3 \mathrm{H}), 3.77(\mathrm{t}, J=5.5 \mathrm{~Hz}, 1 \mathrm{H}), 3.94(\mathrm{t}$, $J=5.5 \mathrm{~Hz}, 1 \mathrm{H}), 4.07(\mathrm{t}, J=4.0 \mathrm{~Hz}, 1 \mathrm{H}), 4.32(\mathrm{dd}, J=6.0,4.0 \mathrm{~Hz}, 1 \mathrm{H}) ;{ }^{13} \mathrm{C} \mathrm{NMR}(75 \mathrm{MHz}$, 
$\left.\mathrm{CD}_{3} \mathrm{OD}\right) \delta 36.3,58.4,64.2,71.4,74.0,75.8,90.5$; MS (CI) $193\left(\mathrm{MH}^{+}\right)$. HRMS (ES+) for $\mathrm{C}_{7} \mathrm{H}_{17} \mathrm{~N}_{2} \mathrm{O}_{4}$ : Calcd.: 193.1188 Found: 193.1189.

Acetic acid 2,3-diacetoxy-5-acetylamino-4-methoxy-cyclopentyl ester 9. An analytical sample of compound 4 (10 mg) was peracetylated in a 1/1 pyridine/acetic anhydride mixture (4 mL) overnight. EtOAc $(2 \mathrm{~mL})$ was added, and the solvent was evaporated. The crude was purified by silica gel chromatography (elution conditions toluene/acetone $2 / 1$ ) to give 9 (10 mg). ${ }^{1} \mathrm{H}$ NMR (400 MHz, $\left.\mathrm{CDCl}_{3}\right) \delta 2.04(\mathrm{~s}, 3 \mathrm{H}), 2.08(\mathrm{~s}, 6 \mathrm{H}), 2.10(\mathrm{~s}, 3 \mathrm{H}), 3.42(\mathrm{~s}, 3 \mathrm{H}), 3.76$ $(\mathrm{t}, J=5.0 \mathrm{~Hz}, 1 \mathrm{H}), 4.57(\mathrm{ddd}, J=9.0,6.3,5.0 \mathrm{~Hz}, 1 \mathrm{H}), 5.14(\mathrm{t}, J=5.0 \mathrm{~Hz}, 1 \mathrm{H}), 5.34(\mathrm{dd}, J=$ $6.3,4.0 \mathrm{~Hz}, 1 \mathrm{H}), 5.46(\mathrm{dd}, J=5.0,4.0 \mathrm{~Hz}, 1 \mathrm{H}), 5.77(\mathrm{~d}, J=9.0 \mathrm{~Hz}, 1 \mathrm{H})$.

Literature: $2.04(\mathrm{~s}, 3 \mathrm{H}), 2.08(\mathrm{~s}, 6 \mathrm{H}), 2.10(\mathrm{~s}, 3 \mathrm{H}), 3.42(\mathrm{~s}, 3 \mathrm{H}), 3.77(\mathrm{t}, J=4.6 \mathrm{~Hz}, 1 \mathrm{H}), 4.57$ $(\mathrm{ddd}, J=9.0,6.1,4.6 \mathrm{~Hz}, 1 \mathrm{H}), 5.14(\mathrm{t}, J=4.6 \mathrm{~Hz}, 1 \mathrm{H}), 5.34(\mathrm{dd}, J=6.1,3.9 \mathrm{~Hz}, 1 \mathrm{H}), 5.46$ $(\mathrm{dd}, J=4.6,3.9 \mathrm{~Hz}, 1 \mathrm{H}), 5.82(\mathrm{~d}, J=9.0 \mathrm{~Hz}, 1 \mathrm{H})$. 


\section{Biological activities:}

$\alpha$-mannosidase inhibition essays were conducted according to the procedure described in ref. 8: $2.0 \mathrm{mM}$ p-nitrophenyl $\alpha$-D-mannopyranoside, $0.1 \mathrm{M}$ acetate buffer, $\mathrm{pH}$ 4.5. $\alpha$-mannosidase was purchased from SIGMA and its enzymatic activity was checked before inhibition essays. All experiments were conducted in triplicate, and the mean value of $\%$ activity was plotted against concentration logarithm.
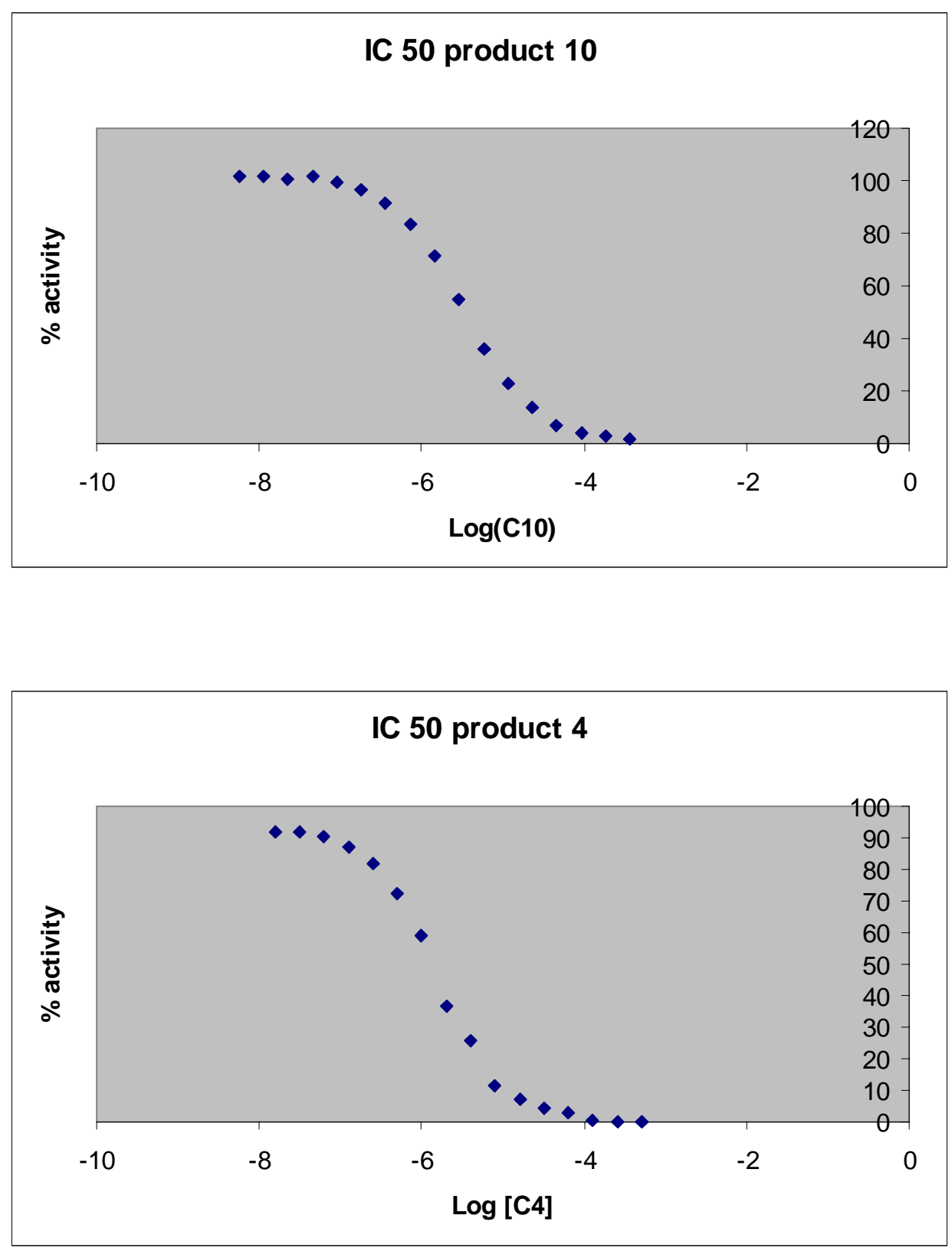


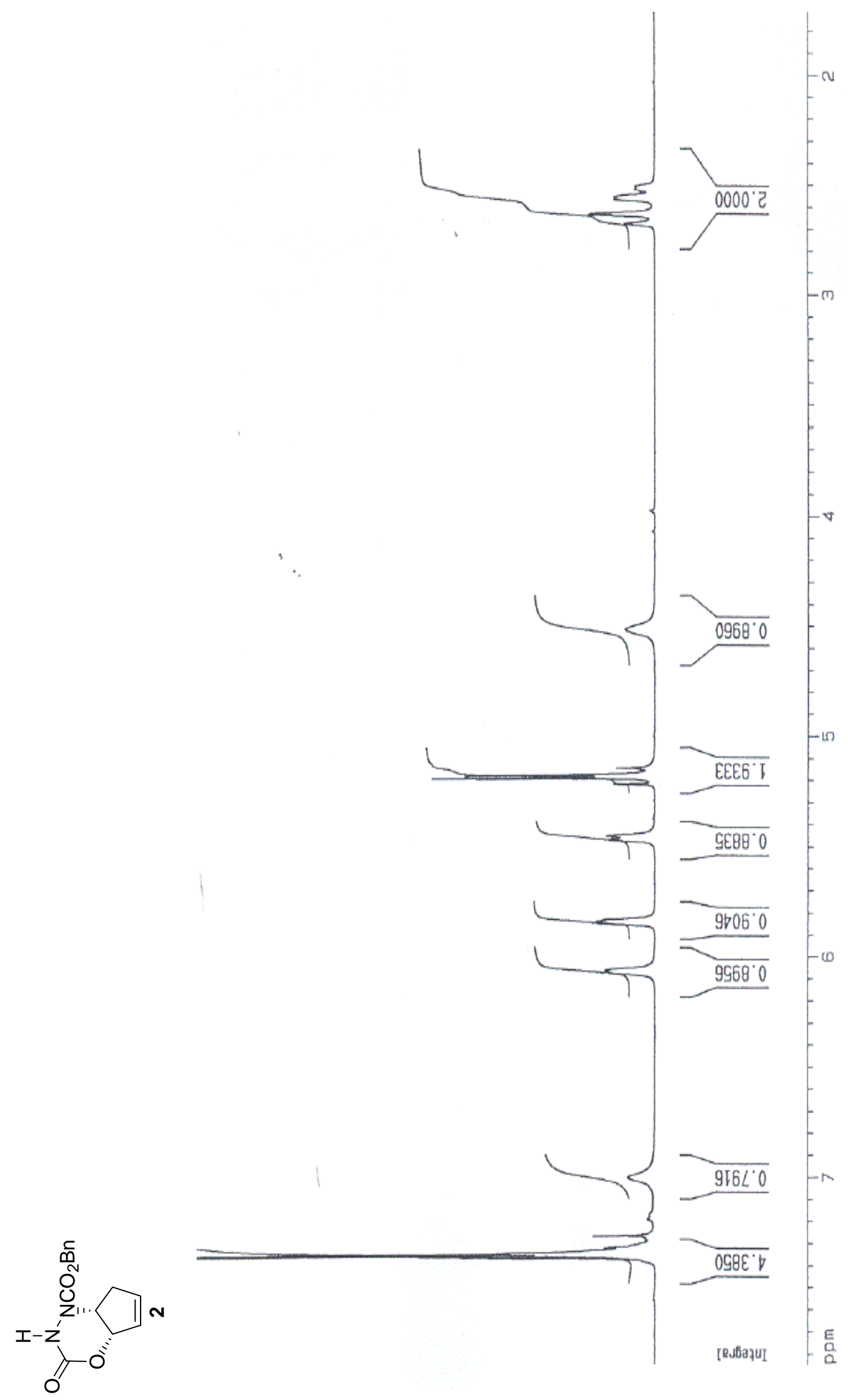


is

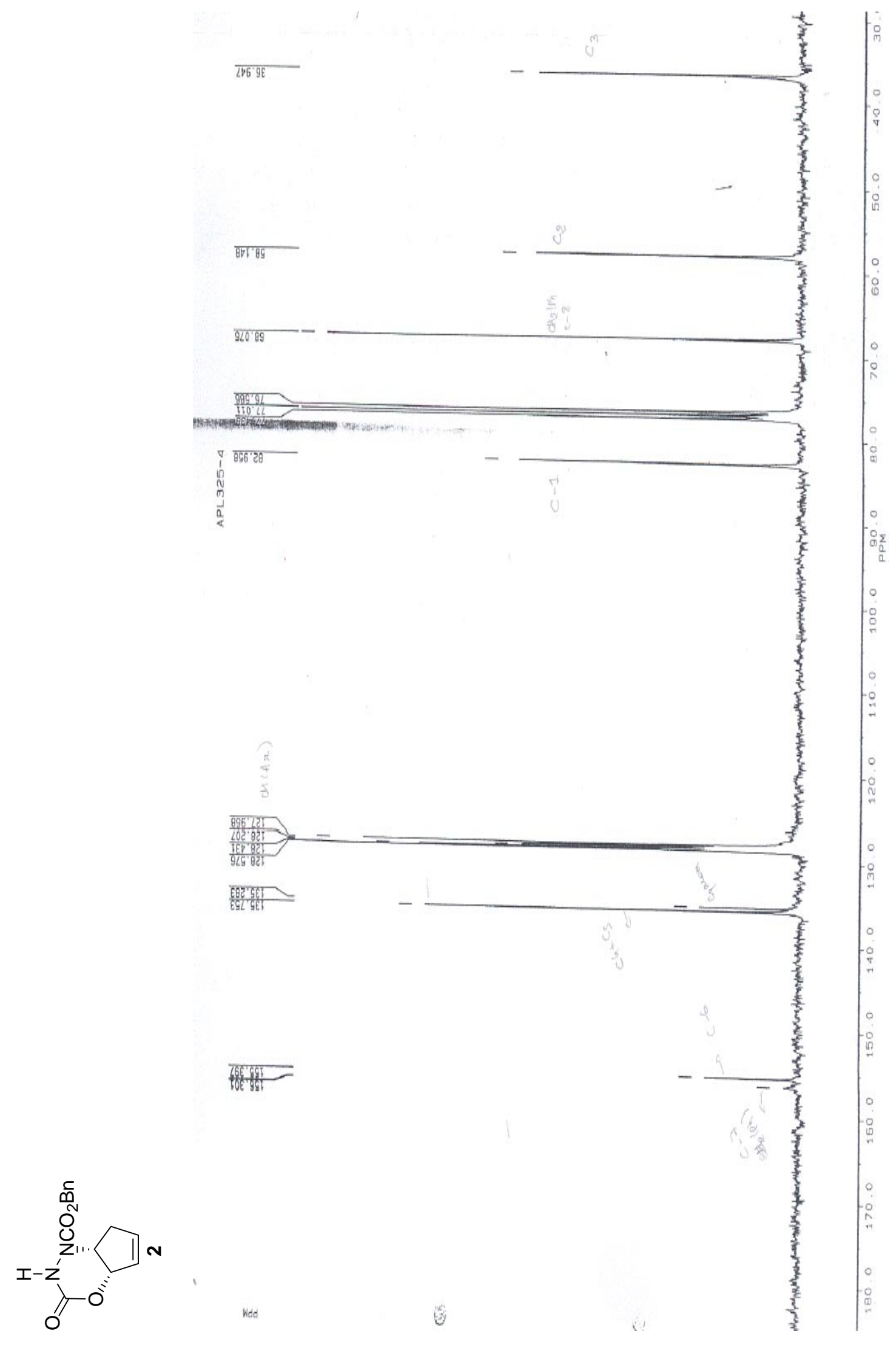


के

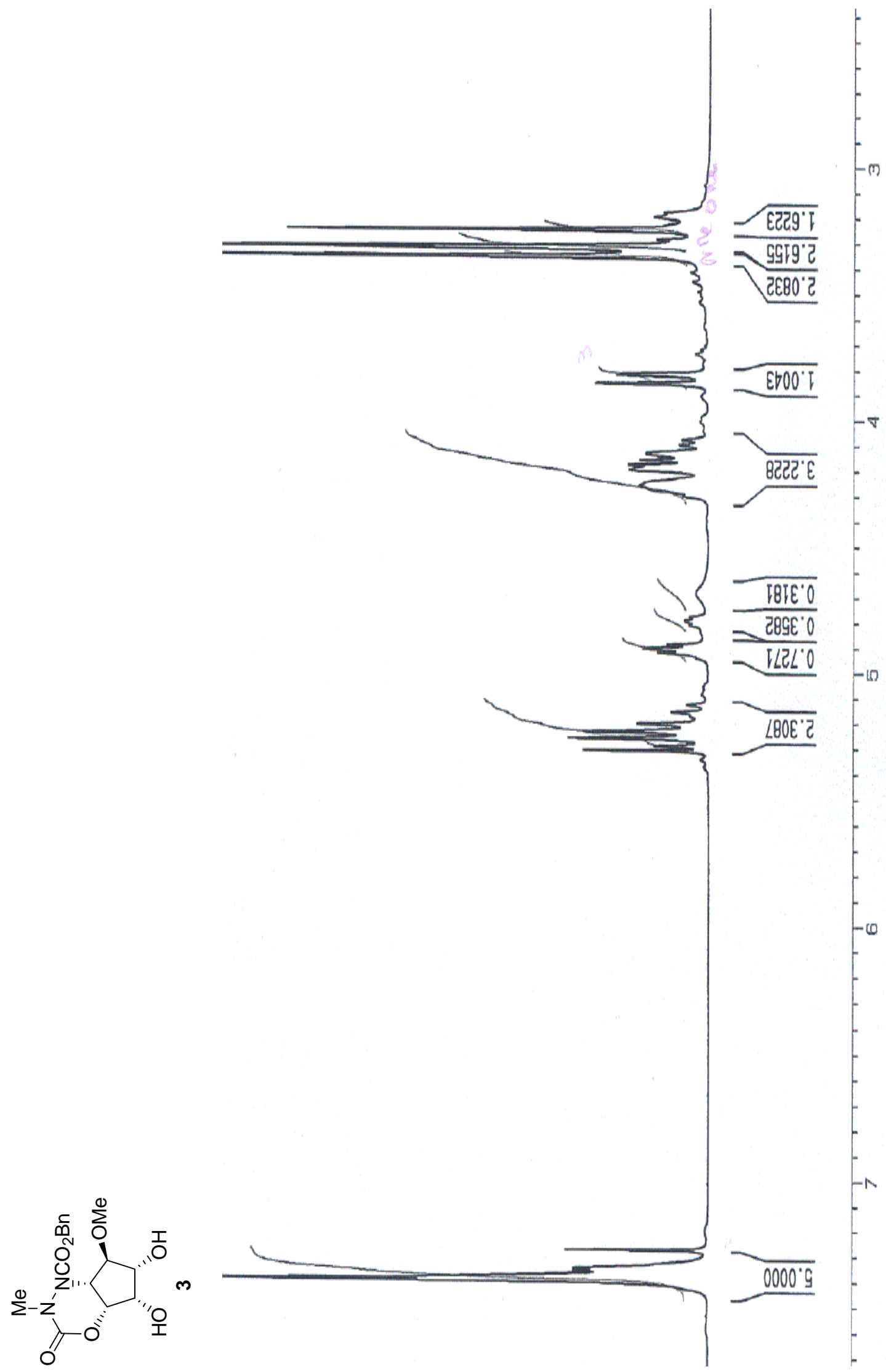


ज

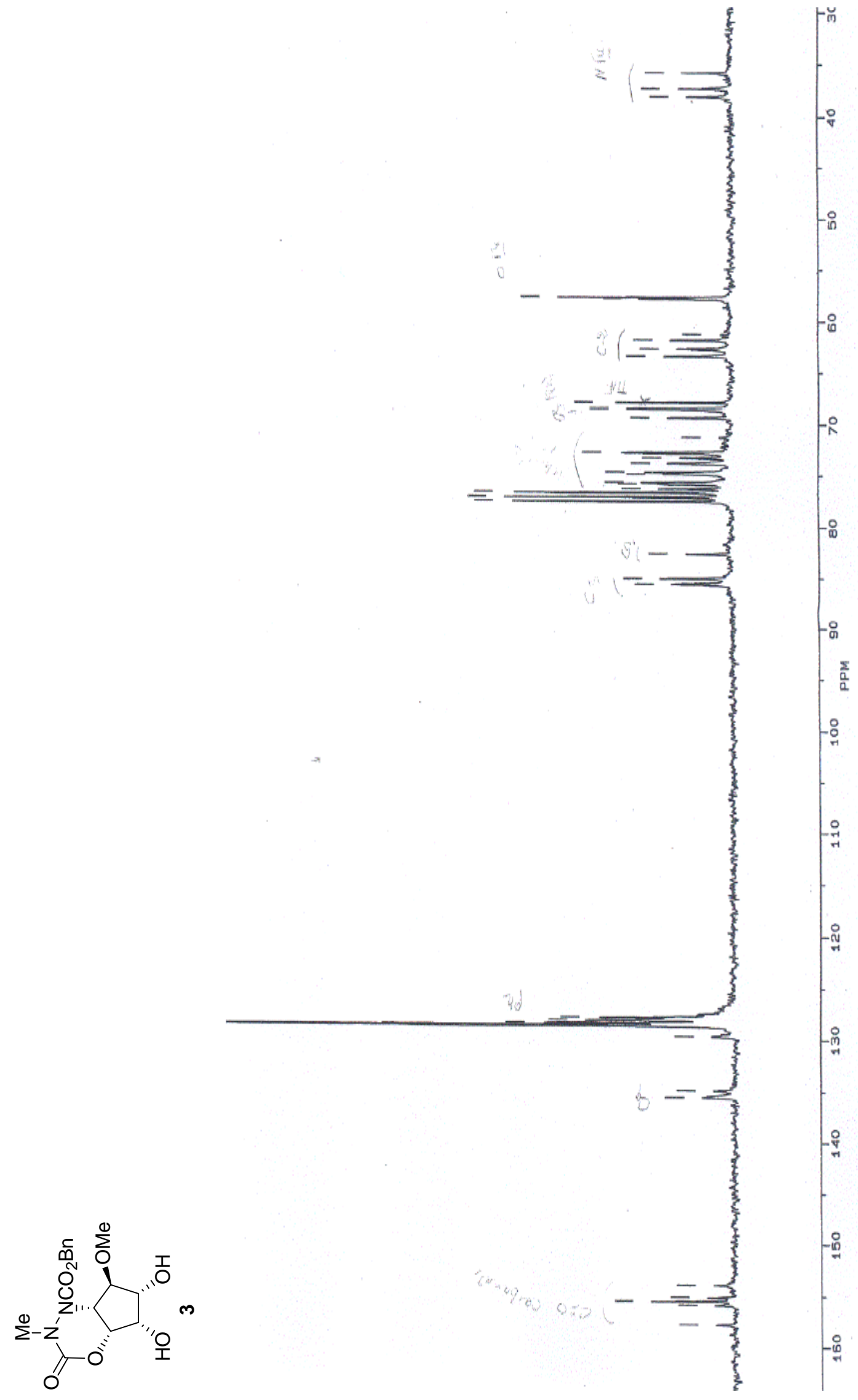


$\frac{1}{6}$

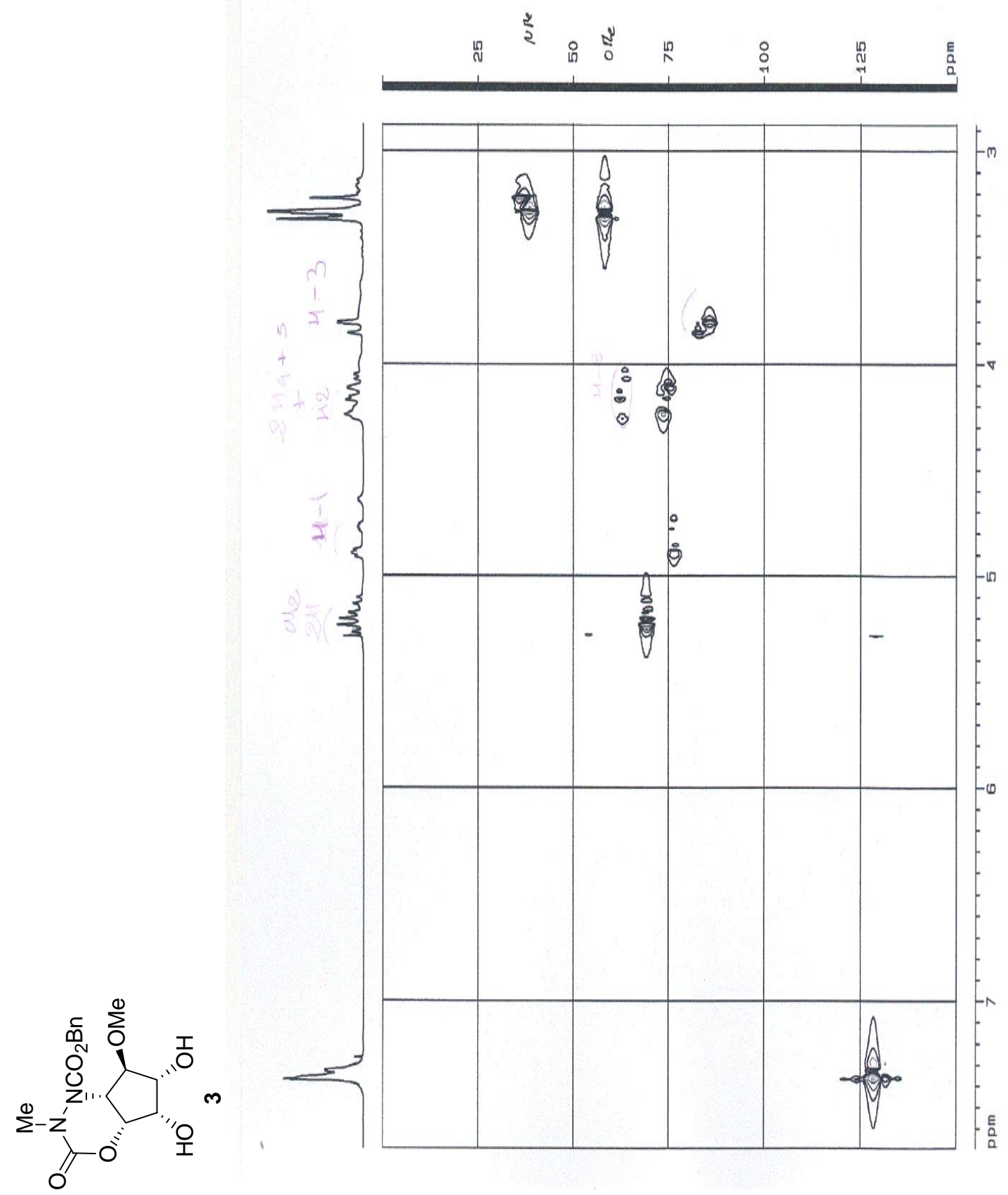


$\frac{m}{n}$

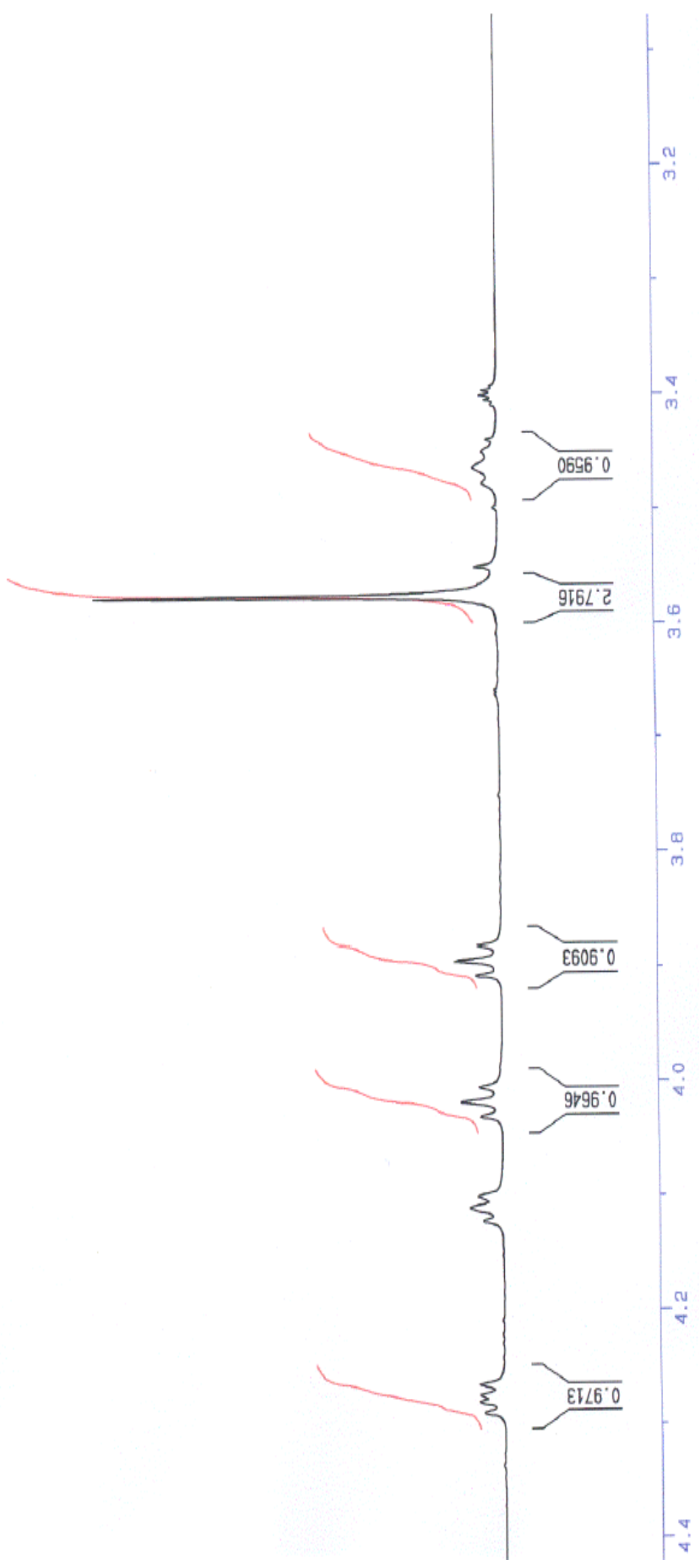


$\frac{ \pm}{n}$

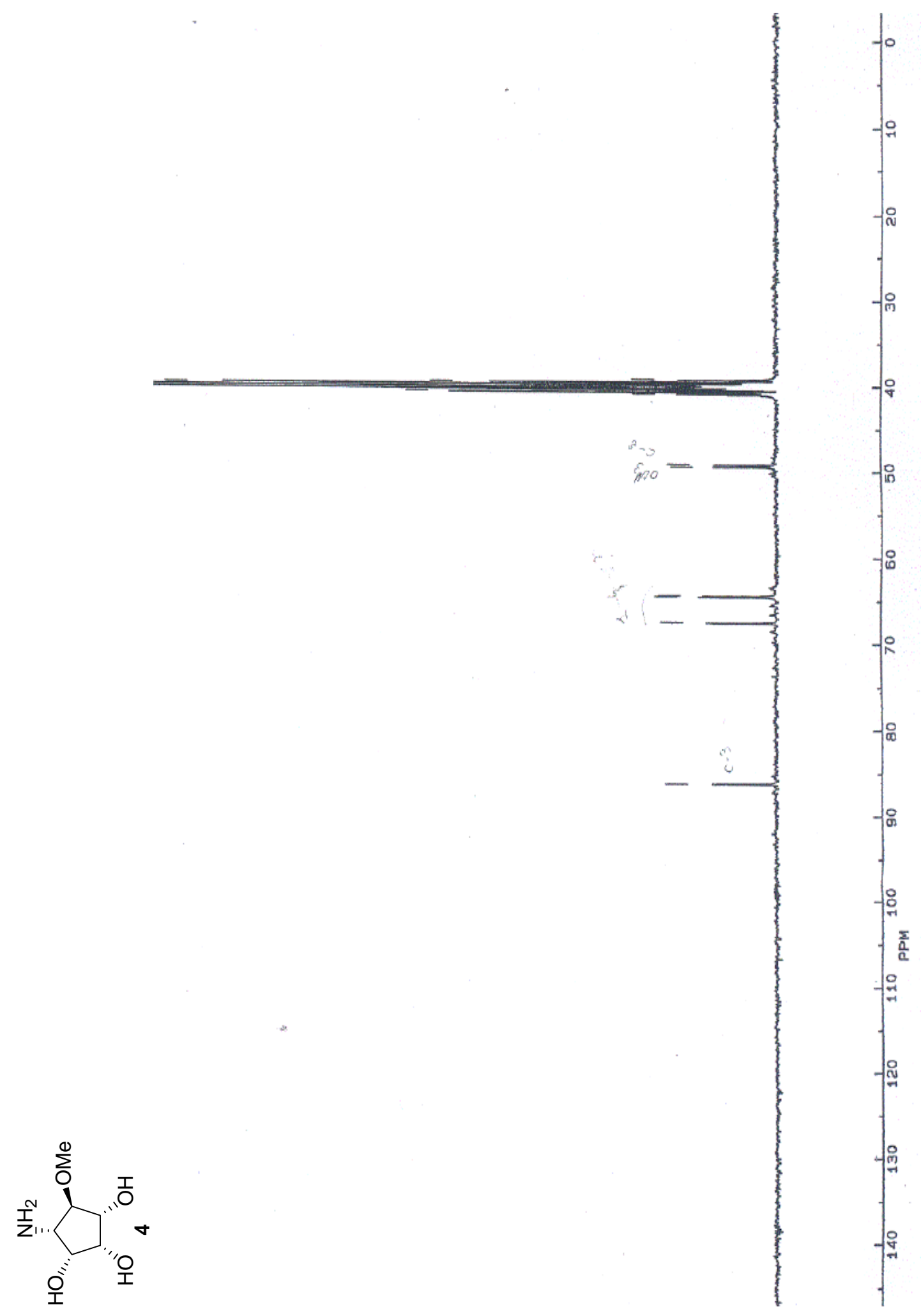


$\frac{n}{n}$

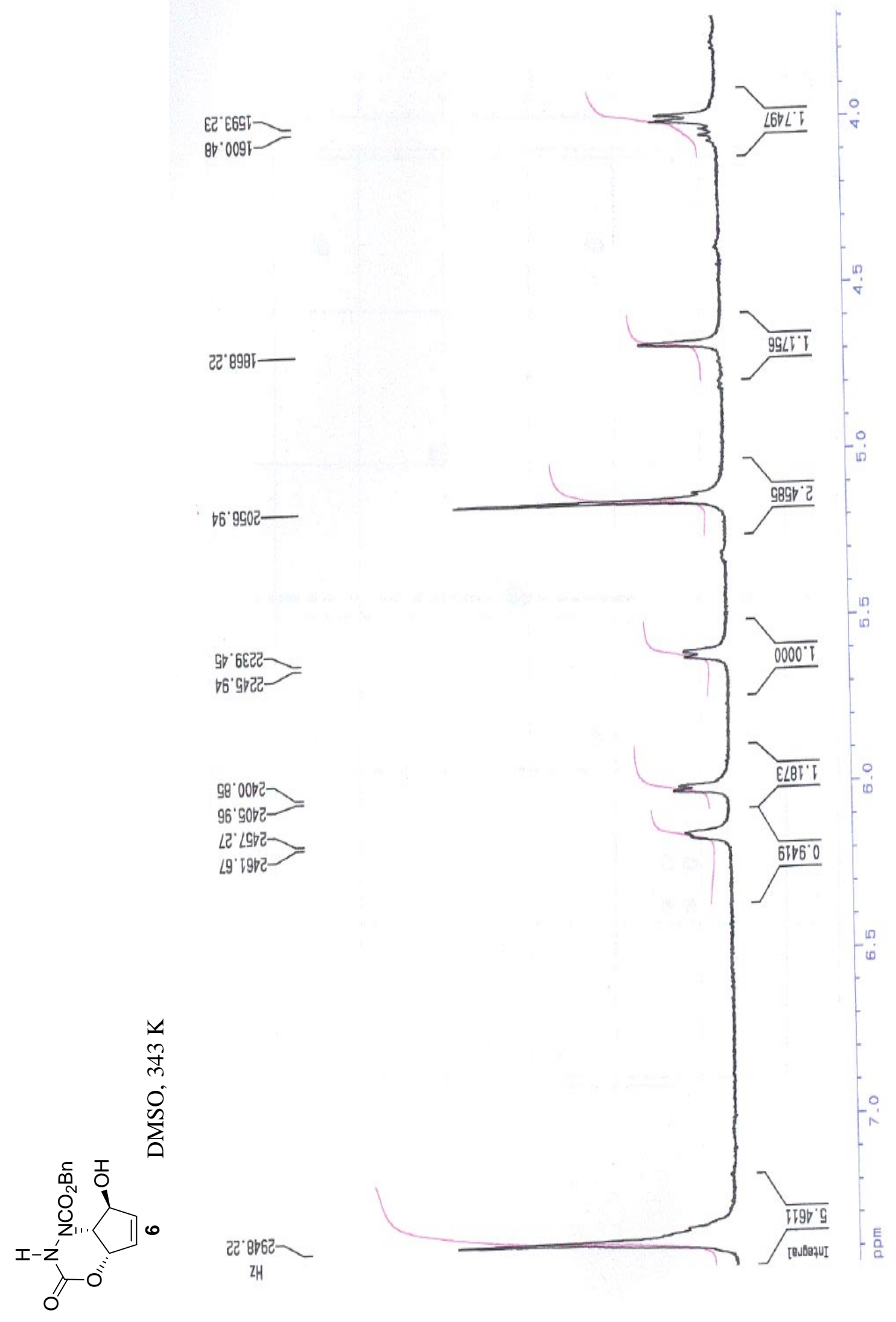


$\frac{6}{n}$

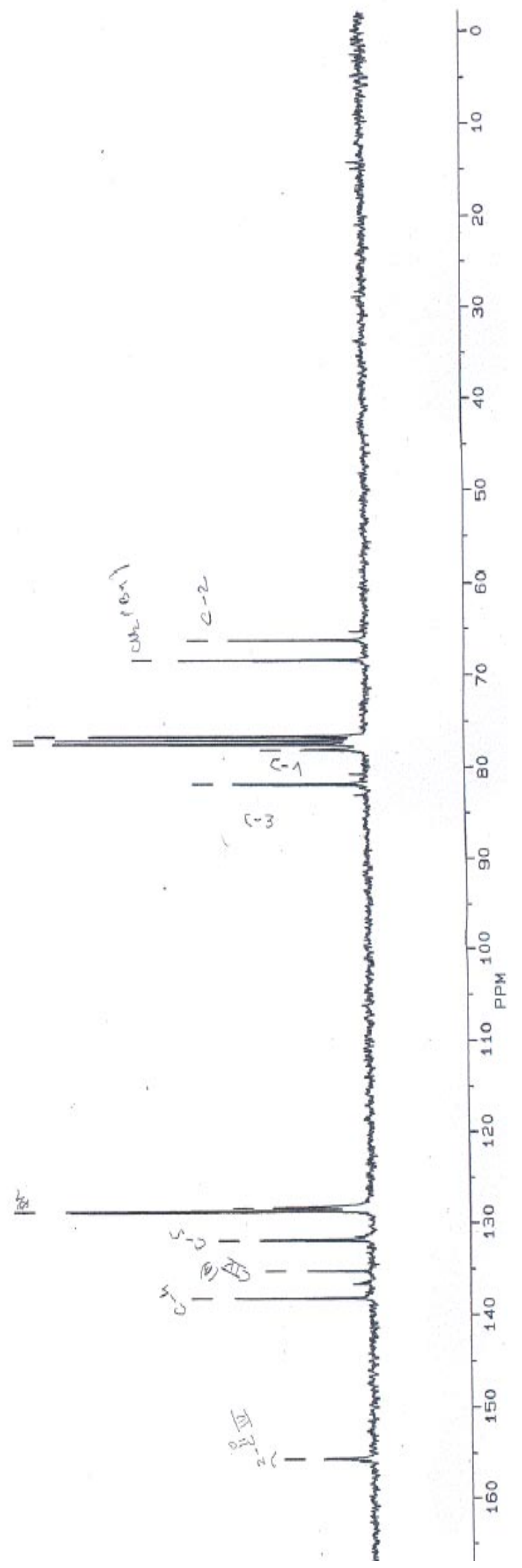


के

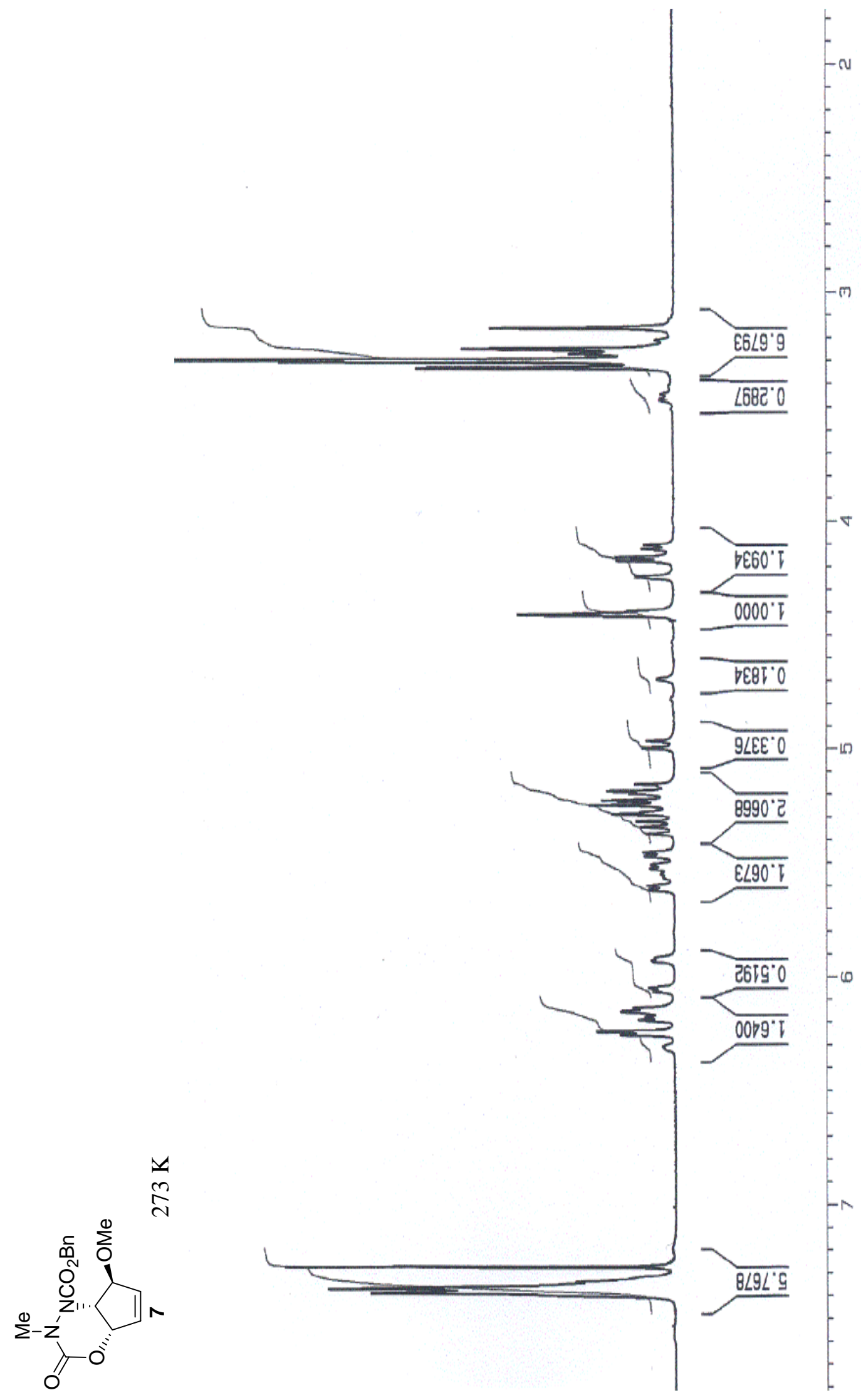


$\frac{\infty}{n}$

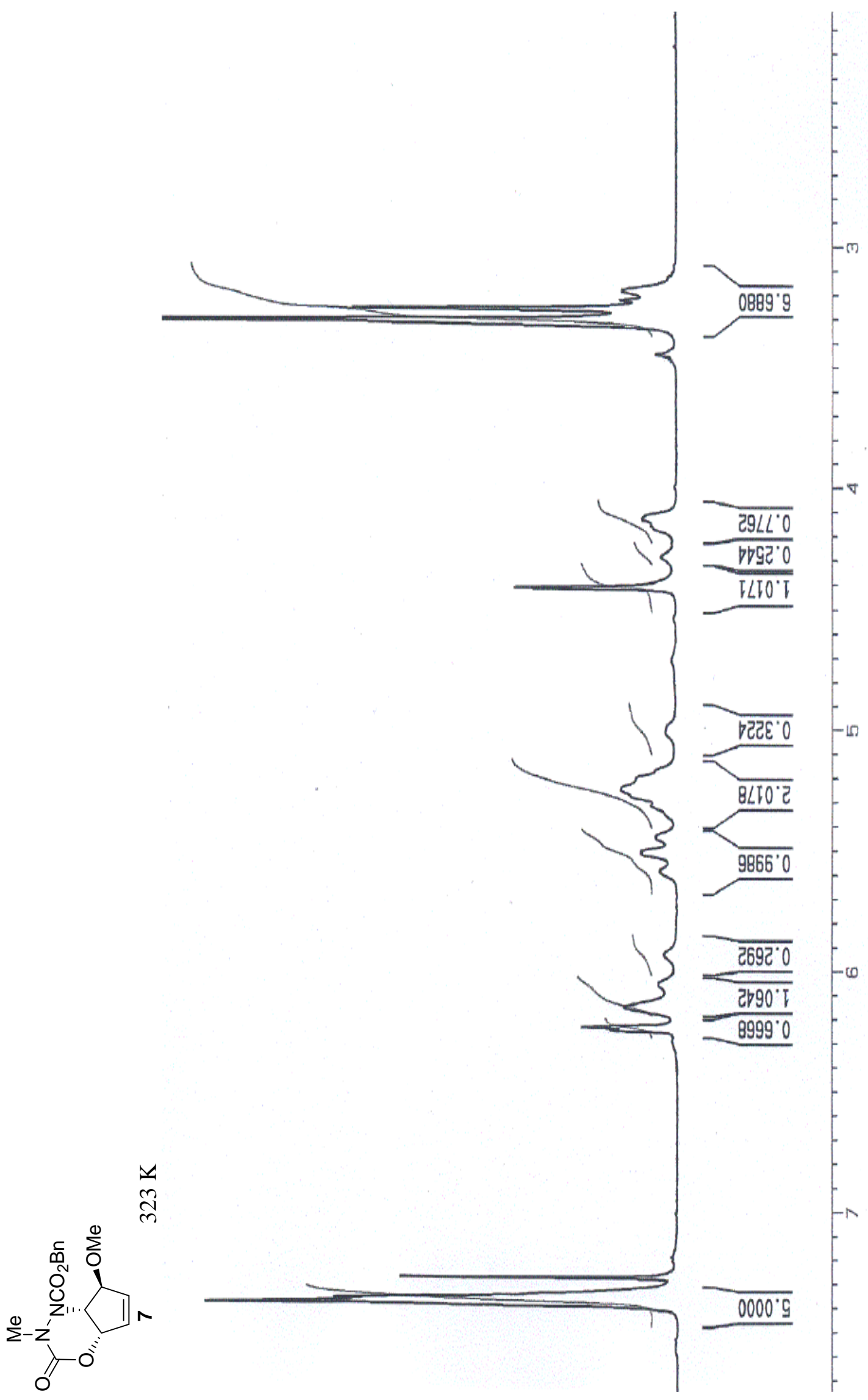


के

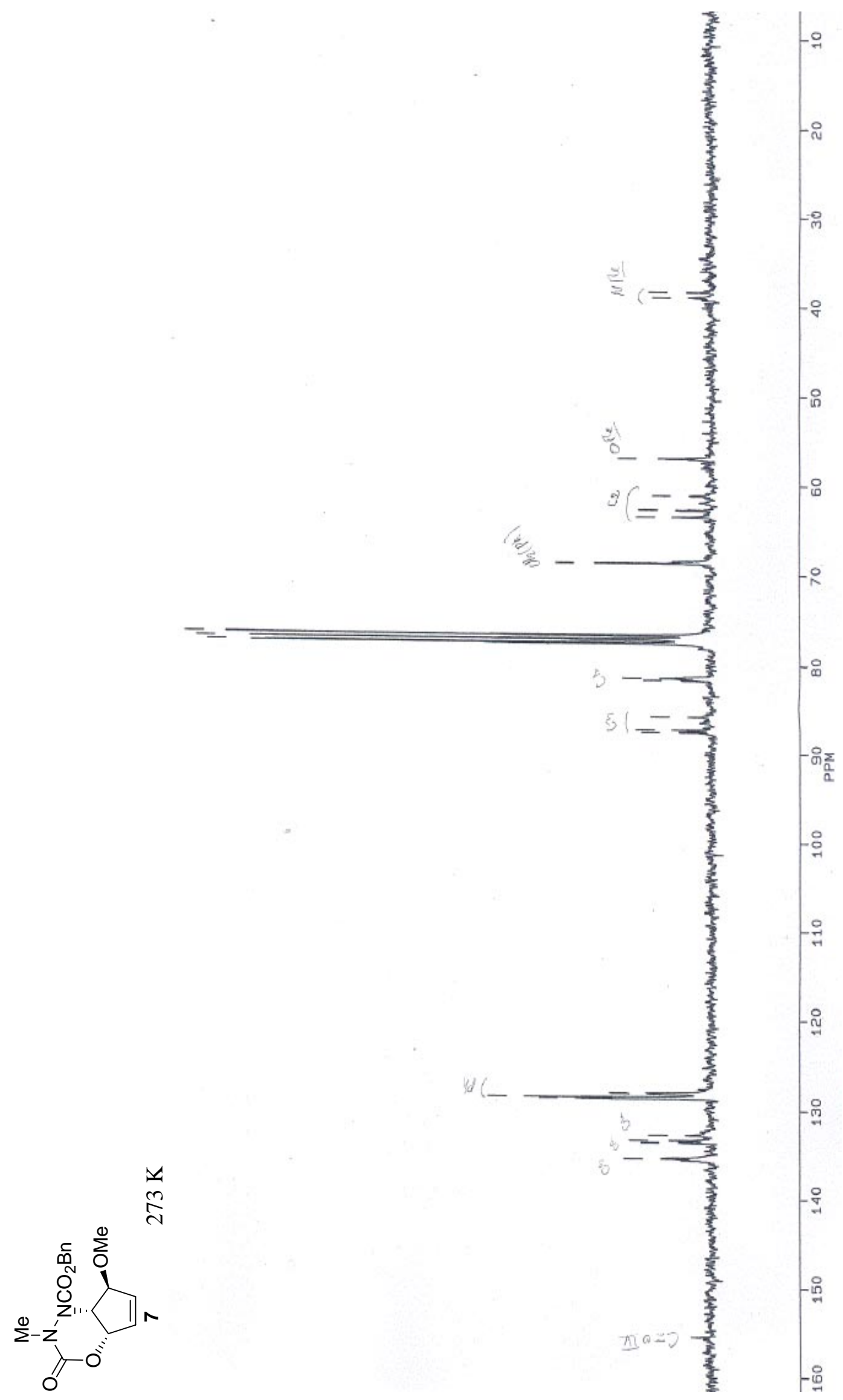


ถิ

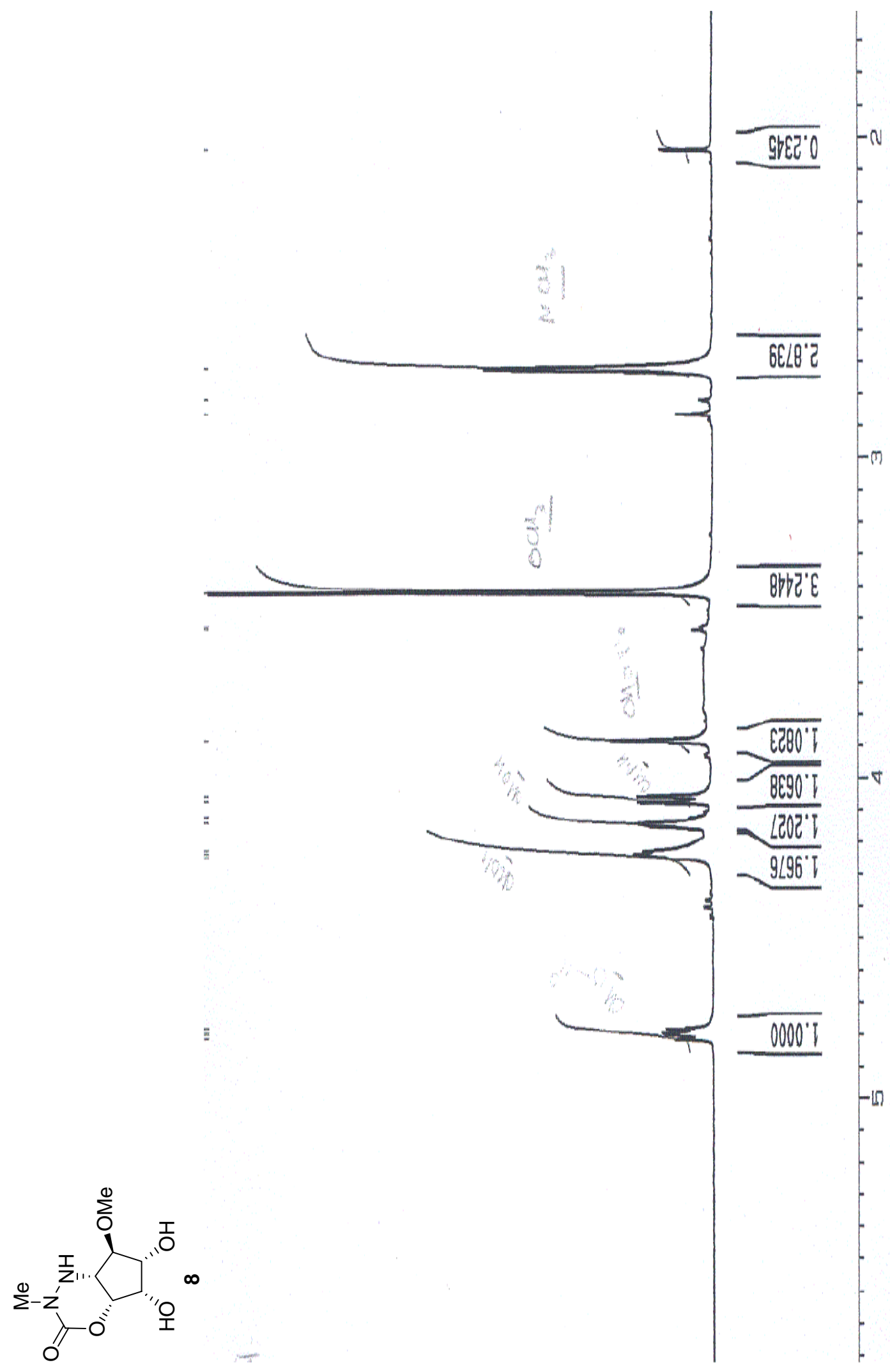


$\overrightarrow{\mathrm{N}}$

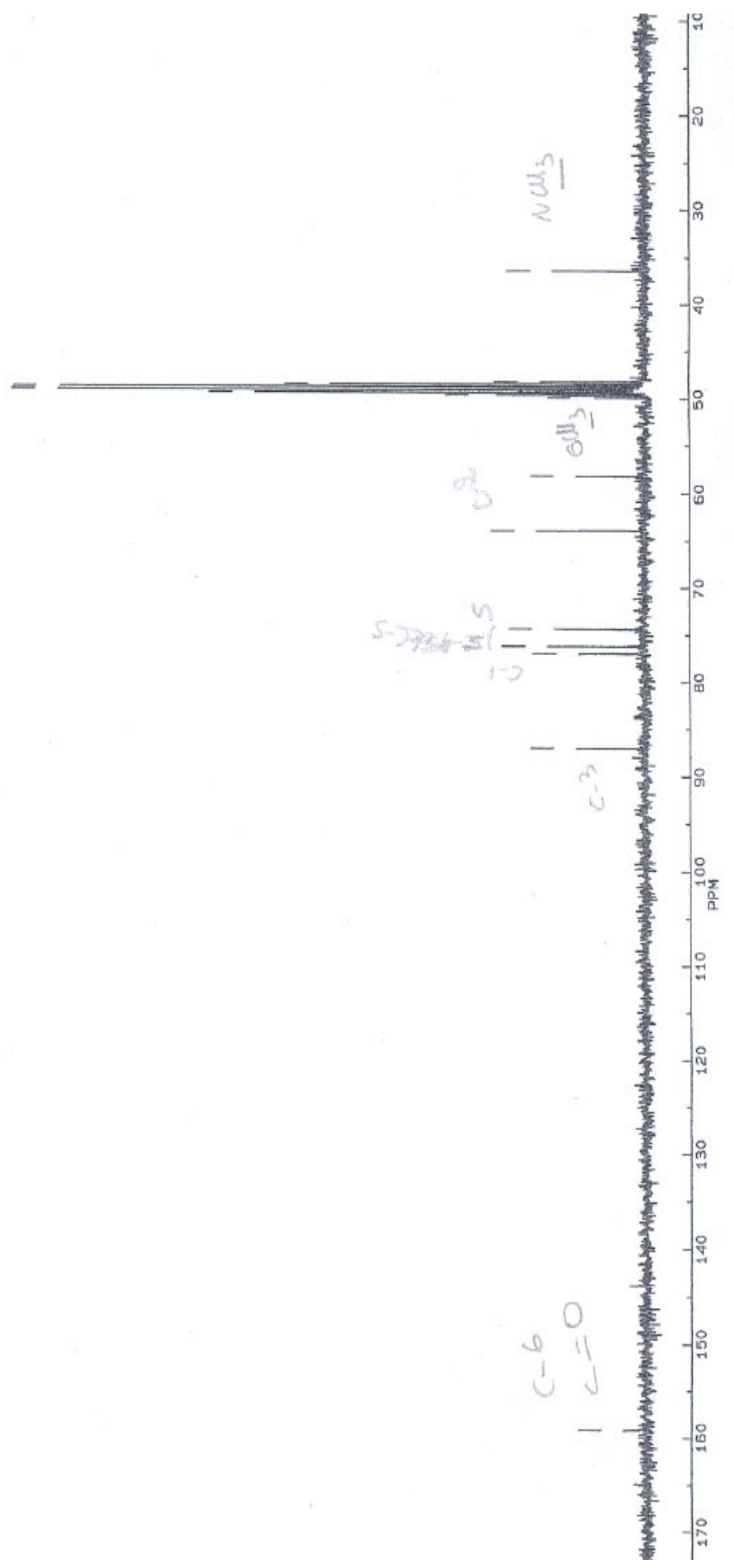


ถู

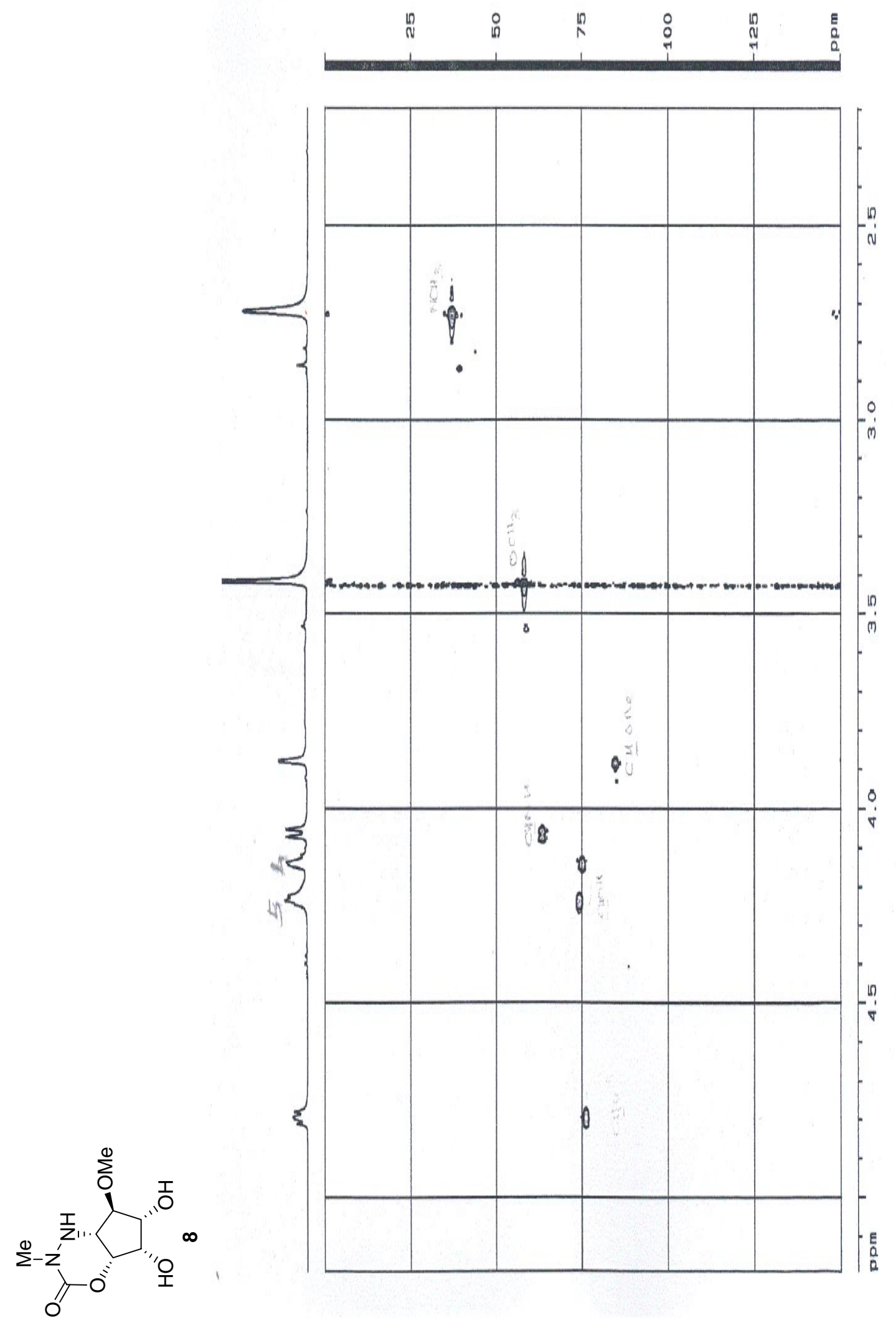


๑

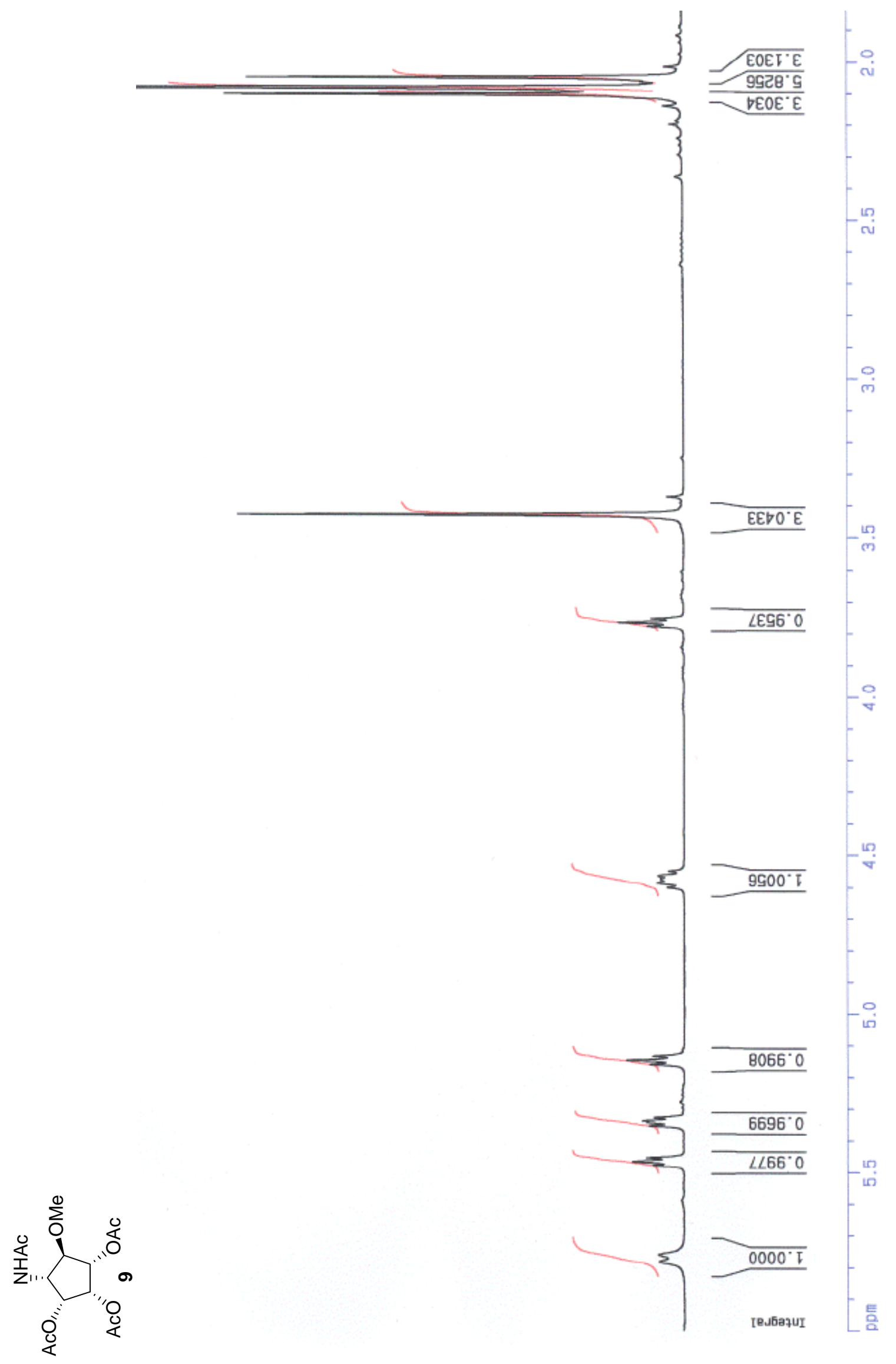


茨

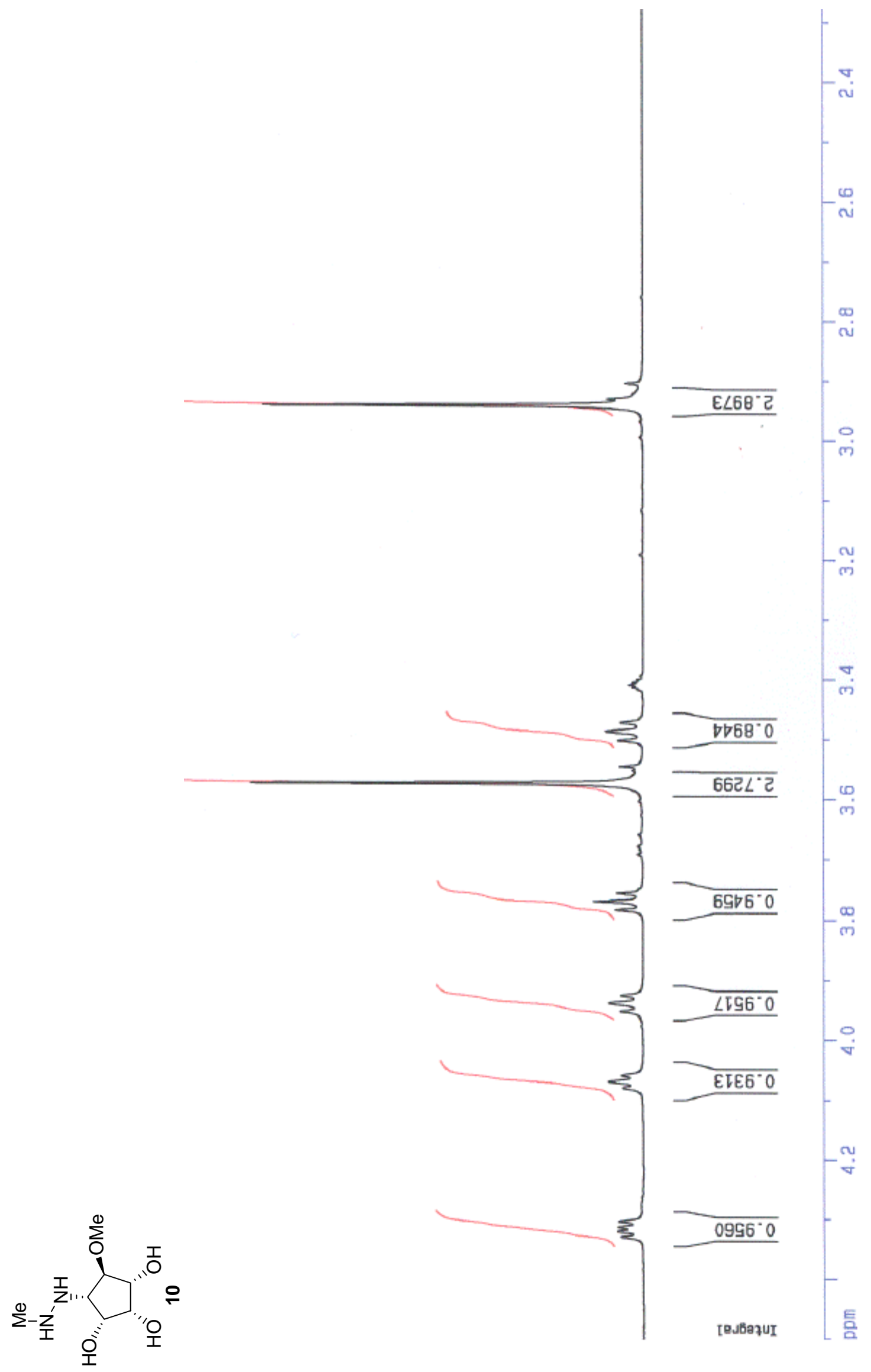




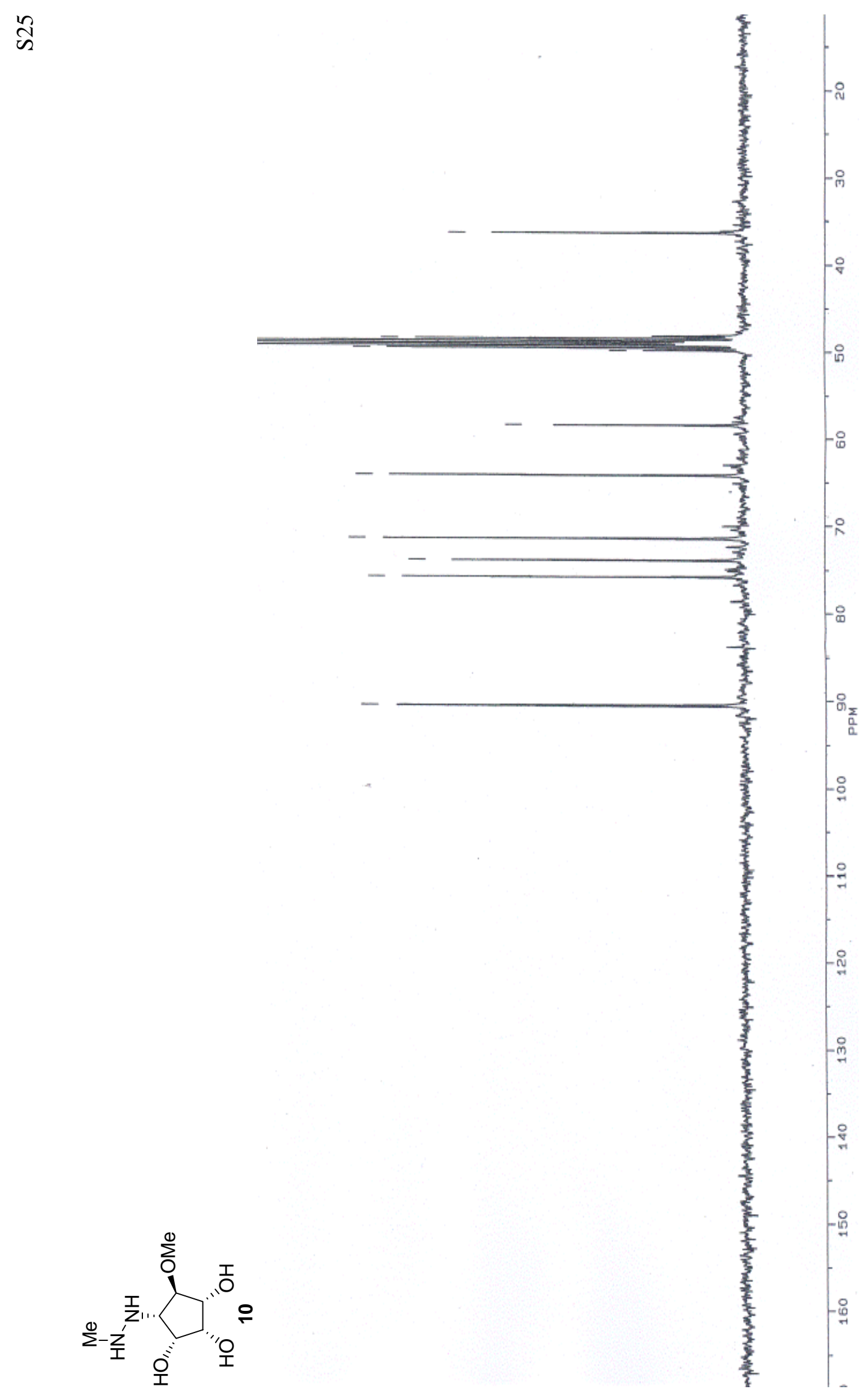

